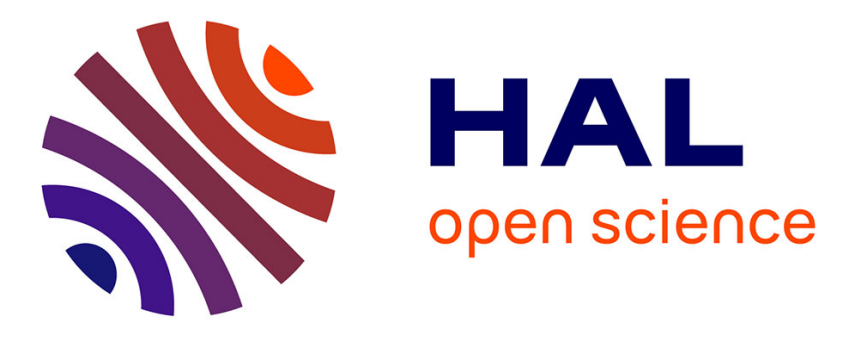

\title{
Design of an Integrated Model for the Real-Time Disturbance Management in Transportation Supply Networks
}

Günther Schuh, Volker Stich, Christian Hocken, Michael Schenk

\section{- To cite this version:}

Günther Schuh, Volker Stich, Christian Hocken, Michael Schenk. Design of an Integrated Model for the Real-Time Disturbance Management in Transportation Supply Networks. IFIP International Conference on Advances in Production Management Systems (APMS), Sep 2015, Tokyo, Japan. pp.144-151, 10.1007/978-3-319-22756-6_18 . hal-01417453

\section{HAL Id: hal-01417453 \\ https://hal.science/hal-01417453}

Submitted on 15 Dec 2016

HAL is a multi-disciplinary open access archive for the deposit and dissemination of scientific research documents, whether they are published or not. The documents may come from teaching and research institutions in France or abroad, or from public or private research centers.
L'archive ouverte pluridisciplinaire HAL, est destinée au dépôt et à la diffusion de documents scientifiques de niveau recherche, publiés ou non, émanant des établissements d'enseignement et de recherche français ou étrangers, des laboratoires publics ou privés. 


\title{
Design of an integrated model for the real-time disturbance management in transportation supply networks
}

\author{
Günther Schuh ${ }^{1}$, Volker Stich ${ }^{2}$, Christian Hocken ${ }^{2}$ and Michael Schenk ${ }^{2}$ \\ ${ }^{1}$ Laboratory for Machine Tools and Production Engineering (WZL) of RWTH Aachen Univer- \\ sity, Aachen, Germany \\ ${ }^{2}$ Institute for Industrial Management (FIR) at RWTH Aachen University, Aachen, Germany \\ \{christian.hocken, michael.schenk\}@fir.rwth-aachen.de
}

\begin{abstract}
In recent years supply chain participants are increasingly suffering the effects of disturbances in transportation supply chains. Both, dynamics in consumer demands and global supply chains lead to a growth in unplanned supply chain events. These can cause from rather manageable disturbances through to complete break-downs of transportation chains, resulting in high follow-up and penalty costs. Consequently, concepts for an efficient supply chain disturbance management are needed, preferably with a real-time identification and reaction to disturbance events. Therefore in the following paper the research results of the German research project Smart Logistic Grids with the focus on designing an integrated model for the real-time disturbance management in transportation supply networks are presented. This includes the introduction of elaborated classification models for disturbances and action patterns as well as an associated costs and performance measurement system. Finally, a procedure model for the disturbance management is presented.
\end{abstract}

Keywords: Supply Chain Management; Supply Chain Disturbances; Supply Chain Resilience; Supply Chain Event Management; Disturbance Management

\section{Introduction}

The complexity of transportation supply chains is steadily increasing by the rising global cross-linking of production and sales regions. They are increasingly exposured to worldwide occurring disturbances. On the other hand the requirements of in time delivery and supply chain security a rising. [1, 2, 3]

The complexity of this development affects not only strategic considerations of supply chain participants, but is also a constant component of their daily business. High requirements on all levels, from the supply chain design top-down to the supply chain execution, need to be fulfilled. The supply chains currently show obvious deficiencies in managing disturbances within their transportation networks. One reason for this situation can be deduced by the missing understanding of disturbances and their impacts on the transportation network as well as by the missing assessment and 
application of reaction patterns. Another reason for this deficiency can be found in the shortcoming of applicable supporting ICT systems. Current systems cannot stand up to the increasing requirements, because their functional scope can neither provide the necessary real-time disturbance identification nor returning valuable action patterns with the required excellence $[4,5]$.

The German research project Smart Logistic Grids is one research example with the focus on overcoming these weak points by designing an integrated model for the real-time disturbance management in transportation supply networks and implementing this model within a software-based disturbance management system [5]. In the following work, the results of the model design are presented. Therefore in the following to chapters, the project itself as well as the methodological approach is described. In the main chapter four the integrated model is presented and finally, an outlook on further research within the project is given.

\section{The Project Smart Logistic Grids}

The project Smart Logistic Grids aims at developing a system for a cross-company disturbance management as well as ensuring improved information availability and a smooth integration of all supply chain partners. The application focus is on industries with a low production depth, e.g., the automotive industry, which rely on a functioning value-adding network. In these transportation supply chains, disturbances pose a high risk for production strategies such as Just-in-time and Just-in-Sequence [6].

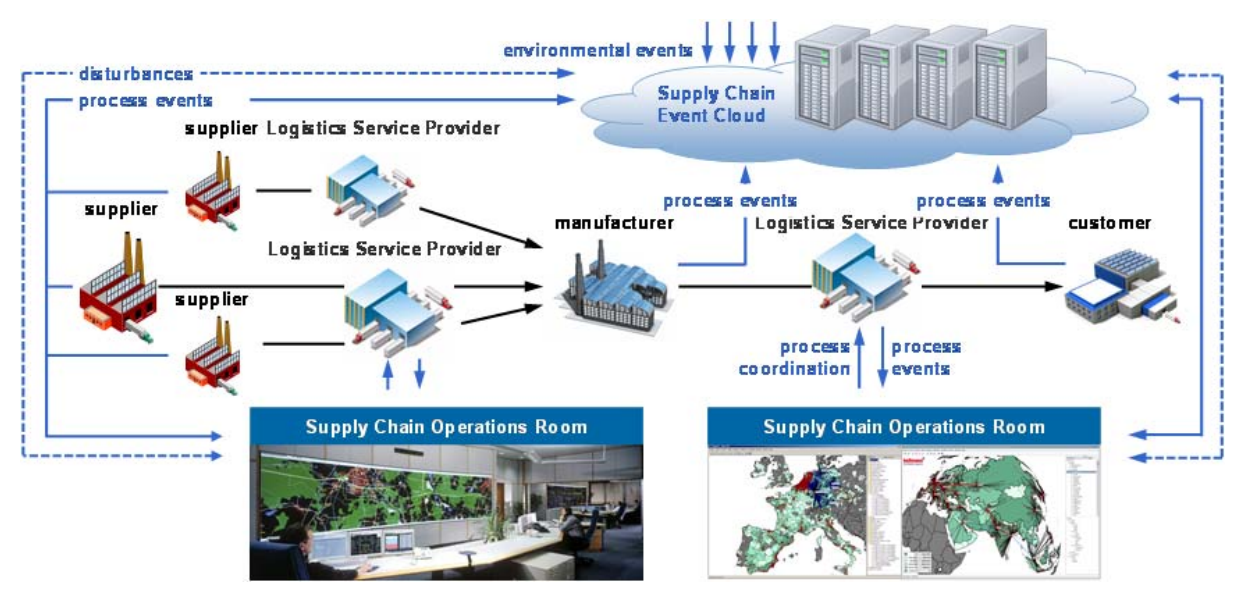

Fig. 1. Vision of the research project Smart Logistic Grids [6]

Therefore, the main targets of the research project are the development of an integrated model for the real-time disturbance management in transportation supply networks as the necessary theoretical basis and its integration into a software-based Supply Chain Operations Control Center and Supply Chain Event Cloud. 
The Supply Chain Operations Control Center focuses on the compilation and visualization of disturbances and action patterns, based on real-time data generated by the logistic network. It represents a central control station and generates action patterns for occurring disturbances, based on an elaborated costs and performance measurement system.

A central Supply Chain Event Cloud provides therefore processed information where all supply chain partners have access to. Operating this cloud requires the recording of the entire logistic network's conditions at any time. Required information will be collected by integrating entirely real-time data such as RFID and GPS data. Additionally, further information will be used for calculating the network status, e.g., order, weather and traffic data.

\title{
3 Methodological approach and preliminary works
}

The methodological approach for the model design is subordinated to the overall approach of the research project. The project itself is divided into ten work packages which can be subsumed into five main project steps. The first step includes the requirement definition for disturbance management in transportation supply chains, the deduction of use cases for the later field testing and the identification of relevant events and disturbances in supply chains, related action patterns as well as important key performance indicators. The first project step has taken place in close collaboration with the industrial partners of the research project. The second step forms the core part of the project as it focuses on the design of the integrated model for an integrated model for real-time disturbance management in transportation supply chain which will be further described in this paper. The third step comprises the implementation of the model into software, whereas in the fourth step the model will be applied and evaluated in several field tests with industrial partners. The fifth step includes, besides the overall project management and the project evaluation, the development of a business model for the above mentioned Supply Chain Operations Control Center and the Supply Chain Event Cloud.

\section{Design of an integrated disturbance management model}

\subsection{Design elements of the integrated disturbance management model}

\author{
Measuring the impacts of disturbances and action patterns on supply chain costs \\ and performance. \\ In the first step a cost and performance measuring system for the evaluation of dis- \\ turbance impacts and action patterns needs to be established. [7] regard therefore the \\ three target figures logistics costs, capital lockup and logistics performance. Capital \\ lockup represents the opportunity costs as a result of committing liquid assets in in- \\ dustry stocks, so that they cannot be invested on the financial market. It is measured \\ as sum of the products of material costs and material units on stock in each time step.
}


As the presented research work is focusing on disturbances and action patterns in transportation supply chains, capital lockup can be neglected, as it is neither affected by the above introduced disturbances nor the corresponding action patterns. Logistics costs result by summing up the costs for production as well as the unit-based stock holding and backorder costs for each time step. Production costs result from the value-adding processing of products. In logistic processes, equivalent costs arise by planning and executing transports, so that in this context, these occurring costs can be defined as process costs. In the context of this project, backorder costs are the most tangible cost values besides the process costs. They are depending on the delivery date deviation and represent follow-up and penalty costs, e.g., using alternative means of transport or contract penalties, caused by a deviation from the agreed delivery date [8].

The logistics performance measures a company's delivery performance that is defined by delivery date deviation between the agreed and actual delivery date. It arises as a result of the total material order quantity and the resulting backlog of unfulfilled order quantities. By contrast to logistics costs and capital lockup, the supply service level evaluates the supply chain performance.

Furthermore, an additional category was introduced to value the ecological impact of effects on the transportation supply chain. Therefore the $\mathrm{CO}_{2}$ emission has been chosen as an adequate key performance indicator.

The following figure shows the overall measurement system for the integrated model of an adaptable transportation supply chains and provides a manageable assessment tool for disturbance impacts and action patterns.

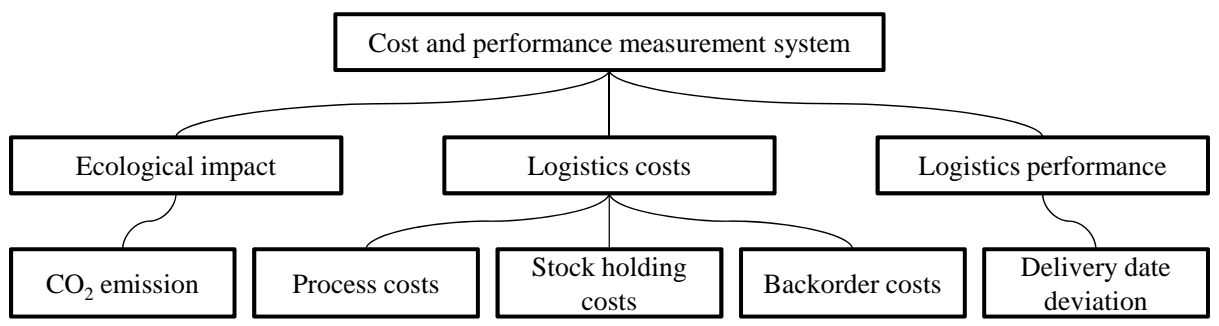

Fig. 2. . Measurement system

\section{Modelling disturbance reasons and impacts.}

Generally, disturbances (both their reasons and impacts) are deduced as a pattern of simple events that means a logical combination of simple events, based on time and place of occurrence. Therefore, a classification model for events in transportation supply chains and a deduction of resulting disturbance types needs to be developed.

For the first classification model the events and their relations are represented using an UML class diagram, which gives the possibility to show different relation types between categories and events.

The developed diagram includes four event levels that become more specific from the upper to the lower level. The first three levels represent categories for aggregating the events, while the fourth level shows actual events. When an attribute applies to all underlying events it is hold in this level. As every event can be described by the oc- 
currence probability, the place and the expected duration (see Fig. 3), all these attributes are allocated to the top level, which only consists of the general and theoretic event.

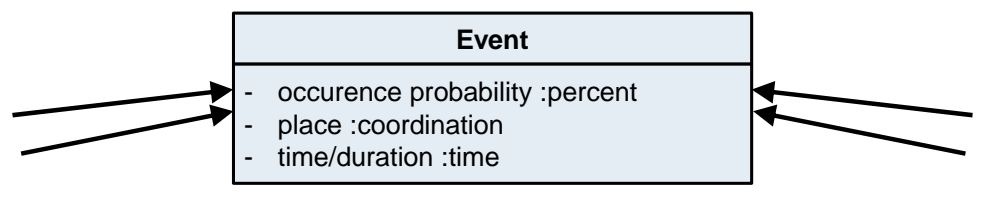

Fig. 3. Event type

Disturbance events can be divided into the categories environment, traffic, politics and process, which form the second level of the diagram. For enhanced transparency and to introduce attributes in a higher level, a third level with further specializations has been included (see Table 1). Meanwhile, the fourth event level shows the actual events.

Table 1. Event classification

\begin{tabular}{llll}
\hline Level 1 & Level 2 & Level 3 & Level 4 \\
\hline Event & Environment & Storms & Storm, Extreme Rain, Fog, Snow \\
& & Natural disasters & Seismic events, Fire (wood) \\
& Traffic & Train & Traffic disruptions, station closures \\
& Road & Traffic jam, road works, accident, stoppage \\
& Sea & Flood, ice, harbor closure \\
& Air & Airport closure \\
& Politics & Attacks & Terrorism, sabotage, piracy \\
& Unrests & War, revolution, rioting, strikes \\
& Customs & Customs delay, temporary transport ban \\
& Processes & Loading & Loading failure, picking failure, missing loading aids \\
& Transport & Deficiency of loading capacities, wrong deliveries \\
& Material & Material defects, material quantity deviation \\
\hline
\end{tabular}

As outlined before, disturbances can be described as complex events that result from a combination of the previous described events and the reference to an actual transportation order. Hence, the disturbances are always connected with the transportation order path of the underlying transport network. As a result of the research work the disturbances can be divided in the following five main disturbance archetypes:

- Transportation delay on a supply chain relation (disturbance reason)

- Resource shortfall (good, loading aid, carrier) for a transport (disturbance reason)

- Demolition or damage of transported good (disturbance reason)

- Transport arriving delay in a supply chain node (disturbance impact)

- Transport departure delay in a supply chain node (disturbance impact) 


\section{Modelling action patterns.}

Based on the preliminary work of identification of typical action patterns with the project partners an adequate classification for action patterns was elaborated as shown in table 2.

Therefore in a first step, possible action patterns need to be assigned to the previously defined three disturbance types. Further, the action patterns have been divided in proactive and reactive actions corresponding to the activity level. That means that action patterns can either be used as reactive measures in case of an occurring disturbance or as preventive measure to reduce disturbance occurrences. As a further characteristic for classification, the planning and control level of the specific action pattern in terms of a strategic, tactical or operative measure should be determined.

The application of this classification system for action patterns can be seen in the following table as an excerpt for action patterns corresponding to transportation delay related disturbances.

Table 2. Action pattern classification

\begin{tabular}{|c|c|c|c|c|c|c|c|}
\hline \multirow[t]{4}{*}{ Type of disturbance } & \multirow[t]{4}{*}{ Action pattern } & \multicolumn{6}{|c|}{ Activity level } \\
\hline & & \multicolumn{3}{|c|}{ Proactive } & \multicolumn{3}{|c|}{ Reactive } \\
\hline & & \multicolumn{6}{|c|}{ Supply chain planning and control level } \\
\hline & & stra & tact & oper & stra & tact & oper \\
\hline \multirow[t]{4}{*}{$\begin{array}{l}\text { Transportation } \\
\text { delay on specific } \\
\text { transport relations }\end{array}$} & $\begin{array}{l}\text { Consideration of temporary / per- } \\
\text { manent disturbances (e.g. road } \\
\text { works) }\end{array}$ & $\mathrm{X}$ & $\mathrm{X}$ & & & & \\
\hline & Preliminary customer information & & & $\mathrm{X}$ & & & $\mathrm{X}$ \\
\hline & $\begin{array}{l}\text { Re-scheduling of transportation } \\
\text { routes }\end{array}$ & & $\mathrm{X}$ & $\mathrm{X}$ & & $\mathrm{X}$ & $\mathrm{X}$ \\
\hline & Detouring disturbed relation / node & & & & & & $\mathrm{X}$ \\
\hline
\end{tabular}

\subsection{Aggregation of the design elements into an integrated approach for the disturbance management in transportation supply chains}

Based on the above introduced design elements a comprehensive approach for the disturbance management in transportation supply chains has been elaborated which consists of the following three steps:

1. Disturbance identification

2. Analysing and evaluating the disturbance impacts

3. Preparation and application of action patterns

The disturbance identification subsumes real-time data identification from the material flow, the planning system as well as the contextual information, e.g. traffic or weather, in a close and timely proximity of shipments in the network as well as the identification of effects on shipments by quantifying effect relations. 
The aim of analysing and evaluating the disturbance impacts is to determine a prognosis of delivery date deviations on the next node and eventually inform about the occurrence probability as well as resulting costs.

Depending on the measurement system, different action patterns can be proposed. Action patterns normally do not affect the transported resources anymore. Instead, the following transhipment will be rescheduled or the shipment will be transported by a faster mean of transport.

The following figure will therefore show a comprehensive view of the model approach. In this case, based on a real-time disturbance identification the overall delivery date deviation is issued with five days. The model identifies and proposes different action patterns ("Do nothing” vs. "Use faster modality") and indicates the resulting costs and performance values.

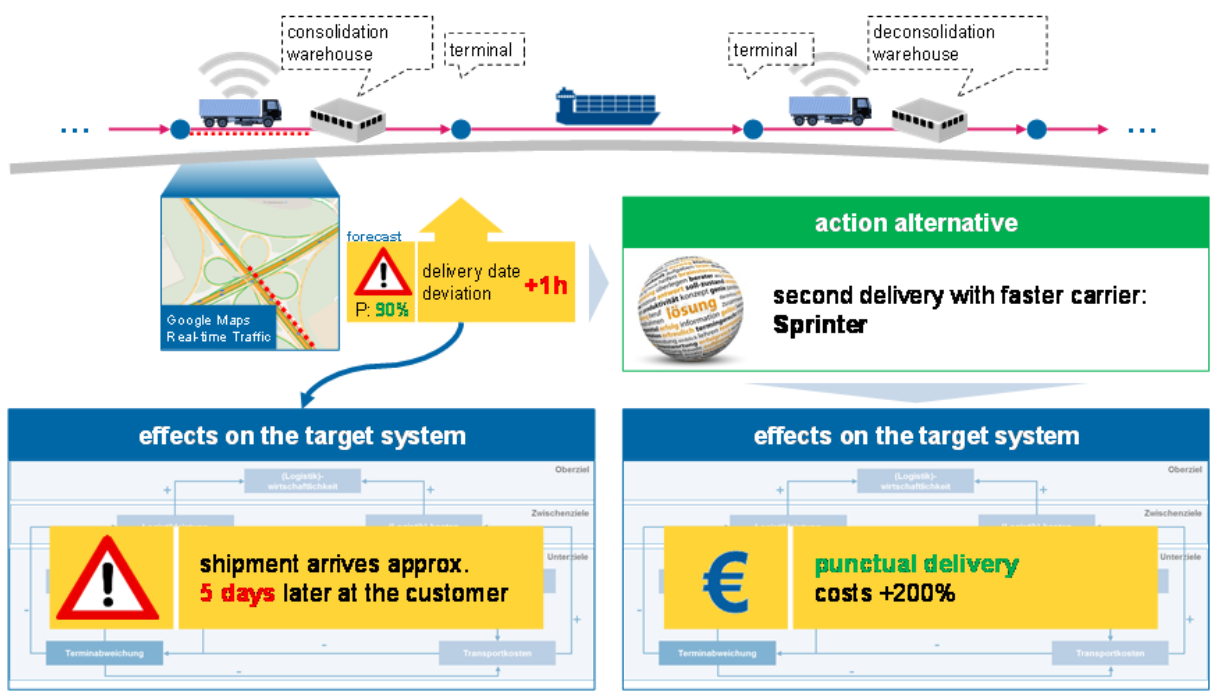

Fig. 4. Example for the integrated disturbance management approach

\section{$5 \quad$ Conclusion and outlook}

The rising vulnerability of globalized supply chains combined with the dynamics in consumer demand patterns lead to increased requirements for coping with supply chain disturbances. Focusing this problem, the presented work shows an eligible design of an integrated disturbance management model for transportation supply chains. It includes classification systems for disturbance events and action patterns as well as a measurement system for valuing both impacts. Finally, these model elements were consolidated in an integrated approach for an efficient disturbance management. All results have been evaluated with the project partners and an extended group of associated industrial companies.

In the further progress of the research project the shown model will be implemented into software based on the existing software PSIglobal ${ }^{\odot}$. For the generation of 
complex disturbance events as described in chapter 4 the Java based rules language Prova is used. Following, the software development the model and software will undergo a multi-level field testing. Starting with tests in an experimental environment based on historical order and disturbance data as far as pilot testing in the daily business of the industrial project partners.

\section{Acknowledgement}

The authors would like to thank the Federal Ministry for Economic Affairs and Energy for the kind support within the research project „Smart Logistic Grids” (BMWi; funding code: 19 G 13002C).

\section{References}

1. Deloitte: Supply Chain Resilience: A Risk Intelligent approach to managing global supply chains. p. 7 (2012)

2. The Business Continuity Institute: Supply Chain Resilience 2011 - An international survey of more than 550 organizations from over 60 countries, which considers the causes and consequences of disruption, the techniques and approaches to identify key supply chains, and methods to gain assurance of resilience capability. The Business Continuity Institute (2011)

3. Henke, M., Lasch, R., Eckstein, D., Neumüller, C., Blome, C.: Supply Chain Agility. Strategische Anpassungsfähigkeit im Supply Chain Management. Bundesvereinigung Logistik (BVL) e.V., Bundesverband Materialwirtschaft, Einkauf und Logistik e.V. (BME), Bremen 10 (2012)

4. Rice, J. B., Caniato, F.: Building a Secure and Resilient Supply Network. Supply Chain Management Review 7.5, 22-30 (2003)

5. Schenk, M., Stich, V.: Managing Supply Chain Disturbances-Review and Synthesis of Existing Contributions. Advances in Production Management Systems. Innovative and Knowledge-Based Production Management in a Global-Local World, Springer Berlin Heidelberg, pp. 262-269 (2014)

6. Prestifilippo, G., Hocken, C., Schmitz, S., Schenk, M.: Smart Logistic Grids: Entwicklung eines Risikomanagementsystems. Anpassungsfähige multimodale Logistiknetzwerke durch integrierte Logistikplanung und -regelung. Unternehmen der Zukunft 14.2, 32-34 (2013)

7. Schuh, G., Stich, V.: Produktionsplanung und-Steuerung 1. Grundlagen der PPS. Springer, Berlin (2012)

8. Fischäder, H.: Störungsmanagement in netzwerkförmigen Produktionssystemen. Deutscher Universitäts-Verlag, Ilmenau (2007) 